\title{
MOODLE NO PROCESSO EDUCACIONAL \\ DE ENFERMAGEM: AVALIAÇÃO NA \\ PERSPECTIVA DO ALUNADO
}

Ronaldo de Souza Moreira Baia, Esleane Vilela Vasconcelos ${ }^{1}$, Silvio Éder Dias da Silva², Karina de Oliveira Freitas ${ }^{3}$ Lúcia Hisako Takase Gonçalves ${ }^{2}$

Objetivo: avaliar parte do ensino de graduação em enfermagem na modalidade de ensino à distância, adotando-se a plataforma MOODLE, Modular Object-Oriented Dynamics Learning Environment, e suas ferramentas. Metodologia: pesquisa ação, desenvolvida na disciplina de Enfermagem em Centro de Terapia Intensiva, utilizando 20\% de sua carga horária na modalidade de ensino a distância, com a participação de 52 estudantes, e devida orientação do corpo discente e docente, com vistas a buscar prática educacional inovada. Resultados: avaliação quantiqualitativa resultou em significativa adequação do MOODLE no processo de ensino de enfermagem. Conclusão: da avaliação da perspectiva do alunado, infere-se que a adoção da plataforma MOODLE, como parte do ensino da enfermagem, representa prática inovada e benéfica, propondo-se seu uso nas disciplinas, em $20 \%$ da carga horária de educação a distância.

Descritores: Enfermagem, Educação a Distância, Bacharelado em Enfermagem, Avaliação Educacional

\section{MOODLE IN THE EDUCATIONAL PROCESS OF NURSING: EVALUATION FROM THE STUDENTS' PERSPECTIVE}

Objective: to evaluate part of the teaching in nursing undergraduate in distance learning modality adopting the MOODLE platform - Modular Object-Oriented Dynamics Learning Environment and its tools. Methodology: action research developed in the Nursing subject at the Intensive Care Center, using $20 \%$ of the workload in distance teaching mode, with the participation of 52 students, and adequate orientation of students and faculty regarding an innovative educational practice. Results: quantitative-qualitative assessment that led to a significant adequacy of MOODLE in the nursing teaching process. Conclusion: From the evaluation of the students' perspective, it is possible to deduce that the adoption of MOODLE platform as part of the nursing teaching represents an innovative and beneficial practice, proposing its use in nursing subjects and $20 \%$ of distance learning education hours.

Descriptors: Nursing, Distance Education, Bachelor in Nursing, Educational Evaluation.

\section{MOODLE EN EL PROCESO EDUCACIONAL DE LA ENFERMERİA: EVALUACIÓN EN LA PERSPECTIVA DEL ALUMNADO}

Objetivo: evaluar parte de la enseñanza de la graduación en enfermería en la modalidad de enseñanza a distancia adoptándose la plataforma MOODLE, Modular Object-Oriented Dynamics Learning Environment, y sus herramientas. Metodología: investigación - acción desarrollada en la disciplina de Enfermería en el Centro de Terapia Intensiva, utilizando 20\% de su carga horaria en la modalidad de enseñanza a distancia, con la participación de 52 estudiantes y la debida orientación del cuerpo dicente y docente, con el objetivo de buscar una práctica educacional innovada. Resultados: evaluación cuantitativa-cualitativa que resultó en una significativa adecuación del MOODLE en el proceso de enseñanza de la enfermería. Conclusión: De la evaluación de la perspectiva del alumnado se infiere que la adopción de la plataforma MOODLE, como parte de la enseñanza de la enfermería, representa una práctica innovada y benéfica. La misma se propone para su uso en las disciplinas de enfermería, en $20 \%$ de la carga horaria de la educación a distancia.

Descriptores: Enfermeria, Educación a Distancia, Licenciatura en Enfermería, Evaluación Educacional.

${ }^{1}$ Enfermeiro. Mestre em Enfermagem. Docente Universidade Federal do Pará-UFPA.

${ }^{2}$ Enfermeiro. Doutor em Enfermagem. Docente UFPA.

${ }^{3}$ Enfermeira. UFPA. 


\section{INTRODUÇÃO}

A plataforma MOODLE, acrônimo de Modular ObjectOriented Dynamics Learning Environment, foi homologada, no Brasil pelo Ministério da Educação, como instrumento oficial para educação a distância. Tal tecnologia oferece um ambiente de atividade social, que focaliza a aprendizagem que acontece enquanto se constroem artefatos para que outros os vejam e os utilizem na propagação do conhecimento ${ }^{(1.2)}$ : cada integrante do sistema tem um papel a desenvolver. Ao professor tutor, por exemplo, cabe orientar o processo de aprendizagem dos alunos, de forma a assegurar que objetivos do ensino sejam alcançados ${ }^{(1-4)}$. Um dos recursos facilitadores do MOODLE é o Ambiente Virtual de Aprendizagem (AVA), mediado pela Tecnologia de Informação e Comunicação (TIC). Tal software aplica o paradigma pautado na filosofia da pedagógica construtivista ${ }^{(5)}$.

Cabe enfatizar que o uso de Tecnologias Educacionais (TE) contribui não só para a aprendizagem dos estudantes, mas para a troca de experiências entre os atores envolvidos, de forma a produzir pertinência cientifica e social, gerar novos conhecimentos e contribuir para o avanço do ensinar uma disciplina implicada. (6.7) $^{-17}$

A incorporação na docência da enfermagem dessa TE pode contribuir para maior eficiência do ensino, uma vez que se trata de instrumento facilitador aplicável em quaisquer disciplinas do curso de graduação, desde que atendidos os requerimentos legais. Assim, o presente estudo teve o propósito de, em regime de teste, adotar o MOODLE como estratégia educacional da disciplina de Enfermagem em Centro de Terapia Intensiva - ECTI, do curso de Graduação em Enfermagem de uma universidade pública, na capital do estado do Pará e, avaliar seu desempenho, da perspectiva do alunado.

\section{METODOLOGIA}

O estudo, uma pesquisa-ação de natureza educacional(8), se desenvolveu, durante o semestre letivo de 2014, implementando-seo programadeensino daECTI, previamente organizado pelo corpo docente, incluindo o pesquisador, segundo os cânones de uso da plataforma MOODLE, junto a 52 alunos do 6ㅇ semestre do Curso de Enfermagem da UFPA.

A pesquisa-ação, de grande aplicação nas ciências humanas e sociais, é uma modalidade de pesquisa que se destaca por seu caráter de atuação conjunta entre pesquisador e participantes do estudo, com o propósito de buscar mudanças e inovações em situações práticas vigentes $^{(8)}$.

O desenvolvimento do MOODLE limitou-se ao ensino de unidades curriculares selecionadas, em $20 \%$ da carga horária total da disciplina, permitido por lei como ensino a distância, no conjunto da disciplina ECTI.
Os estudantes, participantes do estudo, foram previamente informados quanto à pesquisa. Aceitando participar, assinaram o Termo de Consentimento Livre e Esclarecido (TCLE), submetendo-se aos procedimentos preparatórios para realização da disciplina, na modalidade semipresencial, com o aval da Diretoria da Faculdade. Assim, matricularam-se na sala virtual de Curso a Distância intitulada ECTI, da Assessoria de Educação a Distância da Universidade do Pará - AEDI/UFPA, antes do início das atividades curriculares do semestre, como usuários com senha pessoal, para acessar qualquer computador com internet. Os alunos foram capacitados para o acesso a diversas funcionalidades disponiveis no sistema MOODLE.

Os procedimentos da proposta ocorreram concomitantemente: ora o corpo docente e o pesquisador desempenhando $\circ$ papel de docentes, orientando, acompanhando, controlando, respondendo dúvidas ou pedidos de ajuda dos estudantes; ora o alunado cumprindo as determinações requeridas de estudo programado, passo a passo, acessando as ferramentas do MOODLE; ora o pesquisador cumprindo sua função, observando, mantendo registro sistemático dos dados, indagando sobre a emergência de fatos novos.

Realizada a experiência educacional, o alunado respondeu ao questionário adaptado e validado de Peixoto(9) , de avaliação do ensino baseado em MOODLE interativo, compreendendo as dimensões: estratégias aplicadas a atividades; interface gráfica; habilidade do tutor; estratégia de estudo - hábitos de estudo e procedimentos seguidos pelo aluno; ambiente de estudo e de interação. Respondeu, ainda, a questões abertas para uma avaliação subjetiva, bem como a avaliações de desempenho na disciplina. Os dados quantitativos foram tratados com os recursos da estatística descritiva e os dados subjetivos submetidos à análise temática.

Respeitando os preceitos da Resolução n. 466/2012/ CNS/MS, a pesquisa foi aprovada pelo Comitê de Ética em Pesquisa com Seres Humanos da UFPA/ICS, CAAE no 44392315.9.0000.0018.

\section{RESULTADOS}

A atividade curricular da ECTI em questão, de ensino a distância com adoção do MOODLE, iniciou-se com evento presencial de aula inaugural ministrada pela equipe da Assessoria de Educação a Distancia da UFPA e do corpo docente. Introduziu-se o alunado ao acesso à sala virtual e ao uso de todos os recursos planejados para o desenvolvimento de seis módulos, com temáticas específicas selecionadas da disciplina. Os docentes apresentaram aos alunos o desenvolvimento de cada módulo: conteúdo de estudo, objetivos educacionais, trabalhos acadêmicos, uso de estratégias indicadas, carga horária, data final de

32 | Enferm. Foco 2017; 8 (2): 31-35 
encerramento das atividades e avaliação da aprendizagem.

Participaram 52 estudantes de enfermagem que cursavam o 6으 semestre do curso. O perfil era de jovens com idade variando entre 20 e 37 anos, do sexo feminino (78,3\%), não exercentes de atividade remunerada, com renda familiar de um a quatro salários mínimos.

Os estudantes manifestaram-se acerca dessa experiência educacional, atribuindo nota 8 ou mais (escala zero a 10), como modalidade válida e boa para complementar o ensino, recomendando seu uso como estratégia de ensinoaprendizagem. Considerando a avaliação quantitativa referente às dimensões do questionário e à análise dos dados subjetivos, os resultados foram agrupados em unidades temáticas, a seguir apresentadas.

\section{MOODLE - Ferramenta Transformadora do Processo Ensino-Aprendizagem}

Essa plataforma, diferente do modelo tradicional de ensino, permite a construção coletiva do conhecimento e promove autonomia e responsabilização dos alunos pela sua aprendizagem. Tal forma de levar o conhecimento para além da sala de aula é evidenciada de forma positiva pelos participantes: "Foi bastante válida e inovadora, mostrou meio para dividirmos conhecimentos fora da sala. Lá tínhamos mais tempo para discutir assuntos da atividade curricular" (R4); "Foi uma experiência diferenciada. Como a ECTI é pouco "pesada", a plataforma contribuiu disponibilizando materiais para estudo e esclarecendo dúvidas" (R8).

O MOODLE permitiu que dificuldades de vários alunos em compreender determinados assuntos fossem sanadas, pela possibilidade de criação de fóruns de discussão, adicionando material técnico-científico como artigos e vídeos.

As falas abaixo reforçam as palavras: interatividade e aprendizado, de maneira a evidenciar o quanto essa plataforma facilita o desenvolvimento das atividades acadêmicas com outros compromissos pessoais: "A interação com os colegas e principalmente com os professores, assim como o conteúdo didático disponivel, facilitam o estudo e aprendizado, principalmente a internet que você pode acessar onde você estiver" (R29); "Houve maior dinamismo e interação da turma com os professores e tutores e maior aprendizagem, pois estudar pelo MOODLE tornou-se mais leve e dinâmico" (R36).

Assim, o papel do facilitador - o docente - se torna um desafio diário, pois o alunado requer do mediador um constante deslocamento de fonte de informações para uma atuação voltada a responder às necessidades de aprendizagem.

\section{O Aluno - Coautor da Aprendizagem Colaborativa}

Os alunos (36,9\%) identificaram no MOODLE um ambiente cujo aprendizado é construido e compartilhado continuamente, quando observavam que a comunicação fluía de maneira mais flexível e dinâmica. Contudo, dificuldades e pensamentos negativos permearam a busca de conhecimentos, o que pôde ser minimizado mediante adaptação e apoio: “A experiência foi, a princípio, assustadora. Como aluna, mãe e esposa, confesso que o MOODLE me deixou preocupada, mas com o decorrer do semestre vi que não me atrapalhava nas funções domésticas, ele acabou me ajudando no estudo dos conteúdos por flexibilizar as atividades" (R13); "Inicialmente tive medo de não conseguir alcançar as metas. Fiquei parcialmente tranquila quando os professores/tutores me garantiram poder estudar, por disponibilizar prazos para interagir e apoio nas atividades" (R35).

Os desafios de uma nova estratégia educacional podem levar os alunos a temer o desconhecido, considerando-o como intransponível. Nas suas falas, destacaram-se o medo do desconhecido, substituido pela autoconfiança ao se familiarizarem com as ferramentas da plataforma. "A facilidade foi de poder encontrar conteúdos sobre determinados assuntos em um só lugar, podendo me aprofundar nos artigos, vídeos propostos pelos tutores $e$ colegas da plataforma" (R6); "A organização da PAGE que nos direciona aos temas estimulava interesse de forma direta; os exercicios online empolgavam os alunos, faziam interesse dobrar, foi muito valioso" (R40).

A adoção do MOODLE superou as expectativas, por não limitar os estudantes ao que thes era pedido no tema proposto. Incentivando-os a buscar conhecimentos, por meio da integração de múltiplas mídias e recursos, suas discussões eram enriquecidas, reforçando a aprendizagem de modo interativo.

\section{Entraves Possiveis na Utilização da Plataforma MOODLE}

O processo ensino-aprendizagem é uma construção constante do aluno buscar formas de relacionar e somar saberes; os professores auxiliam, elaborando estratégias pedagógicas para facilitar o aluno e a sua interação em ambiente virtual. Contudo, muitos alunos encontravam dificuldades $(47,8 \%)$ relacionadas ao não aproveitamento pleno de recursos do sistema por falta de tempo. "O excesso de atividades de outras disciplinas do semestre nos limitava muito ao uso da plataforma, atividades que também mereciam dedicação" (Rl2).

Observou-se que alunos necessitam de melhor planejamento na organização do tempo de estudo das disciplinas que compõem o bloco curricular do semestre, pois a plataforma MOODLE permite o acesso, a qualquer momento, de materiais para estudo e permanente interação com colegas, alunos e professores.

Por outro lado, os obstáculos mencionados pelos alunos, no contexto local de dificuldades técnicas, requerem 
ser pensados e contornados, considerando a necessária disponibilidade do computador e de conexão de internet. “...] eu acessava a internet nas horas vagas na própria universidade ou na casa de amigos, era um pouco frustrante, porque precisava me distanciar dos colegas para "caçar" computadores disponíveis, algumas vezes sem almoçar para postar algo "bacana" ou falhas de internet, no horário que dispunha para estudar" (R35).

Apesar dessas dificuldades, atualmente, o computador se tornou imprescindivel fonte de estudo e de busca de material. Além do mais, a instituição de ensino permite, incondicionalmente, o uso das bibliotecas e dos laboratórios de informática aos alunos de cursos integrais, como o de enfermagem.

A plataforma MOODLE promove um aprendizado que mobiliza alunos a gerar e construir conhecimento autônomo em regime de colaboração: “Como acadêmico, na plataforma, aprendi a compartilhar conhecimentos, ideias, fazer reflexões e críticas com os colegas e professores, de modo que um fosse complementando o conhecimento do outro" (Rll); "As diversas fontes da plataforma possibilitavam os alunos a construírem suas próprias idéias a respeito de determinado assunto, em torno de um determinado autor" (R12).

Dessa maneira, os depoimentos (45\%) mostram que esses alunos conseguiram identificar, na plataforma, um espaço de construção do conhecimento, com mais consistência, de conteúdos absorvidos de maneira crítica e reflexiva.

\section{Avaliação do MOODLE - O Alunado Como Principal Avaliador}

As reações dos alunos, aos procedimentos realizados e disponibilizados pelos docentes tutores da atividade curricular de ECTI, se resumem na avaliação dos procedimentos da estratégia MOODLE baseada em 17 itens, cuja pontuação em cada item variava de 1 a 10. As médias foram, em sua maioria, iguais ou superiores a 8, demonstrando desempenho semelhante entre os alunos. Ficou demonstrada a facilidade de manuseio da plataforma e semelhança de opiniões em torno da média, com valores próximos de excelência. Observouse, ainda, que as respostas dos alunos revelaram qualidade no ambiente de estudo, com exceção nos procedimentos de conexão com a Internet, cuja avaliação foi de 6,7.

Tal desempenho, fruto de familiarização com o ambiente virtual de exploração de ferramentas, como Fórum, Biblioteca, Tira-dúvidas, Bibliografia, Arquivos para download, Mural de avisos, Links e Fotos, propiciaram participação nas diversas funcionalidades do MOODLE.

Por fim, a comparação de médias de avaliação obtida pelos alunos na disciplina ECTI, em sua parte de ensino presencial de 7,17 (DP 1,35) e a parte do ensino baseado em MOODLE de 7,95 (DP 1,44), resultou em diferença estatisticamente significativa, segundo o teste estatístico t pareado (t-critico $=2,0075 ; p=0,0005$ )

\section{DISCUSSÃO}

A literatura cientifica aponta o uso das TIC como novo caminho para as metodologias de ensino-aprendizagem e nova possibilidade de educação em enfermagem, sustentada na construção do conhecimento pelo aluno e no desenvolvimento de capacidades como inovação, criatividade, autonomia, comunicação e colaboração ${ }^{(10-12)}$. Permite também maior interação e participação nas discussões de conteúdos propostos, pois o aluno deixa de ser um receptor passivo para se tornar ativo no processo ensino-aprendizagem ${ }^{(13)}$

Essa postura de colaboração entre os envolvidos no ensino presencial é limitada pelo pouco tempo disponível em sala de aula; em contrapartida, a liberdade de participação se amplia pelo maior tempo disponível e acesso a diversos materiais sobre os temas em discussão. O MOODLE é mais do que um simples espaço de publicação de materiais: ele oferece ferramentas para estimular os alunos a buscar conhecimentos de acordo com sua necessidade e, em muitos casos, pudemos observar essa busca de novos domínios ${ }^{(10,14)}$.

De uma forma geral, os alunos revelaram que o processo de aprendizagem foi significativo, avaliando-se como sujeitos ativos imbuídos de compreensão em busca de novas informações e cujas motivações internas e conhecimentos prévios eram valorizadas, considerando que, a partir de sua postura ativa, construíam sua própria aprendizagem(15,16). Sob a perspectiva dos alunos, o MOODLE possibilita uma boa comunicação, facilitando sua interação com o conteúdo e o professor responsável e facilitador no ensino-aprendizagem de ECTI, comprovadamente uma valiosa ferramenta de apoio ao ensino presencial. Destaca-se que o professor/ tutor tem papel fundamental no sucesso do uso do MOODLE, pois é quem estimula a participação do aluno mediante interação, favorecendo o aprimoramento da construção do conhecimento, do estímulo ao raciocínio crítico e reflexivo, permitindo construir novos elos com a realidade ${ }^{(10)}$

O estado do Pará tem a particularidade de sua grande extensão territorial, com alguns municípios contando apenas com acesso fluvial. Além disso, deve-se considerar a baixa qualidade de conexão de acesso à internet. Nesse particular, a avaliação dos alunos, com média de 6,7 pela baixa conexão de internet, é fato relevante e pertinente, configurando-se como um dos fatores que podem dificultar o uso da plataforma MOODLE no ensino, no contexto regional em questão.

Para conferir a eficácia do ensino por adoção do MOODLE, como uma TIC alternativa, a comparação de médias obtidas pelos estudantes na avaliação da disciplina, da parte de unidades modulares de ensino com uso do MOODLE com a de unidades de ensino sem seu uso, resultou em diferença

34 Enferm. Foco 2017; 8 (2): 31-35 
estatisticamente significativa. De fato, o método MOODLE permitiu que os alunos melhorassem seu desempenho como: conciliação da atividade curricular com outras atividades; acesso ao computador nos horários disponíveis para estudo; e habilidade e disponibilidade dos docentes, direcionando atividades e interações esclarecedoras sobre assuntos abordados. A liberdade em desenvolver estudos tende a potencializar as capacidades especificas de cada aluno, ajudando-o a obter crescimento intelectual e a consciência de que será um futuro profissional, de forma que se sinta impulsionado a buscar um aprendizado com qualidade(17)

Embora o presente estudo tenha a limitação de ter se realizado em contexto de uma única testagem e restrito, tal resultado tem a corroboração de uma pesquisa experimental mais ampla, realizada em uma Faculdade de Enfermagem de São Paulo, com o mesmo objeto de estudo ${ }^{(18)}$

\section{CONCLUSÃO}

$\mathrm{Na}$ perspectiva dos alunos, o MOODLE se mostrou importante ferramenta de auxílio ao processo ensinoaprendizagem, por permitir maior interação dos alunos entre si e com os professores, promovendo a construção compartilhada do conhecimento. O MOODLE se configurou como espaço educativo alicerçado nos princípios da andragogia e da criatividade dos discentes, cuja interação dialética entre teoria e prática fortalecia a noção de que o aprendizado ocorre mais eficientemente em ambientes colaborativos.

Tal constatação de avaliação do MOODLE, como valiosa ferramenta de ensino da enfermagem, impõe-nos propor seu uso nas disciplinas, em $20 \%$ da carga horária de EAD permitida por lei, por contribuir para um ensino mais dinâmico, interativo e colaborativo, imprimindo um ensino alternativo e inovado das disciplinas de enfermagem.

\section{REFERÊNCIAS}

1.Franco CP. A Plataforma Moodle como Alternativa para uma Educação Flexivel. Rev EducaOnline. [Internet] 2010 [acesso em 2017 jan 18]; 4(1). Disponivel em: http://www.latec.ufrj.br/revistas/index. php?journal=educaonlineEpage=articleEop=viewEpath\%5B\%5D=97.

2. Souza APL, Silva DCS, Matos KC. A importância da utilização de ferramentas do MOODLE na educação à distância. Revista EDaPECI São Cristóvão (SE), 2015 set/dez; 15(3):656-69.

3. Prado C, Casteli COM, Lopes TO. The virtual environment of a research group: the tutors perspective. Rev Bras Enferm USP. 2012;46(1):246-51.

4; Avelino CCV, Borges FR, Inagaki CM, Nery MA, Goyata SLT. Desenvolvimento de um curso no Ambiente Virtual de Aprendizagem sobre a CIPE. Acta Paul Enferm. 2016; 29(1):69-76. DOI http://dx.doi. org/10.1590/1982-0194201600010

5. Alves ED, Ribeiro LSN, Guimaraes DCSM, Costa CMA, Peixoto HM Martins EF et al. MOODLE - folio para o ensino em saúde e enfermagem: avaliação do processo educacional. Rev Eletr Enf [Internet]. 2012 [acesso 2015 set 20];14(3):473-82. Disponivel em: http://www.fen.ufg.br/revista/ vl4/n3/vl4n3aO3.htm.

6. Nespoli G. Os domínios da Tecnologia Educacional no campo da Saúde. Interface (Botucatu). 2013 out/dez;17(47):873-84.

7. Costa PB, Prado C, Oliveira LFT, Peres HHC, Massarollo MCKB, Fernandes MFP et al. Fluência digital e uso de ambientes virtuais: caracterização de alunos de enfermagem. Rev Esc Enferm USP [online]. 2011 [acesso 2015 set 20];45(esp):1589-94. Disponivel em: http://www.scielo.br/pdf/reeusp/ v45nspe/v45nspea08.pdf.

8. Mallmann EM. Pesquisa-ação educacional: preocupação temática análise e interpretação. Cadernos de Pesquisa. 2015; 45(155):76-98.

9. Peixoto HM. Avaliação de disciplinas semipresenciais de graduação e pós-graduação na área de promoção da Saúde na Universidade de Brasília [dissertação]. Brasilia (DF): Universidade de Brasilia; 2012.
10. Crivelaro LP, Garbin MC, Gallana LMR, Gambaro B, Pereira NR. O comportamento do aluno em um curso a distância dentro do ambiente MOODLE: contrapontos entre a ótica inicial e seu uso atual. In: Amaral SF, Souza MIF, Garbin MC. Ambientes virtuais de ensino-aprendizagem. Campinas (SP): FE/UNICAMP; 2010

11. Lara EMO, Lima MFR, Mendes JDT, Lima VV, Petta HL. A arte de facilitar em um curso de especialização: tecendo com os fios das metodologias ativas. Rev Espac Saude. 2014; 15(1):870-1.

12. Nespoli G. Os dominios da Tecnologia Educacional no campo da Saúde. Interface (Botucatu). 2013 out/dez;17(47):873-84

13. Cardoso PMO. O processo de interação na educação a distância na perspectiva do e-TEC Sergipe. In: VI Colóquio Internacional "Educação e Contemporaneidade": [Internet]. Anais, 20 a 22 de setembro de 2012 [acesso 2015 set 20]; São Cristóvão (SE); 2012. p. 1-8. Disponivel em: http:// educonse.com.br/2012/eixo_08/PDF/63.pdf.

14. Grossi TH. O MOODLE como ferramenta de apoio ao ensino presencia em uma escola particular de ensino médio [dissertação]. Lavras (MG) Universidade Federal de Lavras, Minas Gerais: 2014.

15. Costa PB, Prado C, Oliveira LFT, Peres HHC, Massarollo MCKB, Fernandes MFP et al. Fluência digital e uso de ambientes virtuais: caracterização de alunos de enfermagem. Rev Esc Enferm USP [online]. 2011 [acesso 2015 set 20];45(esp):1589-94. Disponivel em: http://www.scielo.br/pdf/reeusp/ v45nspe/v45nspea08.pdf.

16. Alves ED. Ranços e avanços na utilização da internet para o ensino superior de enfermagem no Brasil. Rev Panam Enfermería, 2004: 2(1):14-23.

17. Lillis S, Gibbons V, Lawrenson R. The experience of final year medical students undertaking a general practice run with a distance education component. Rural Remote Health. 2010:10(1):1268 [12-20].

18. DeDomenico EBL, Cohrs CR. Plataforma MOODLE na construção do conhecimento em Terapia Intensiva: estudo experimental. Acta Paul Enferm. 2016; 29(4):381-9. 